\title{
Determinants and Outcomes of Mortality among Extremely Preterm Infants From a Tertiary Hospital in Thailand: 15-Year Experience
}

\author{
Waricha Janjindamai, M.D., Anucha Thatrimontrichai, M.D., Supaporn Disneevate, M.D., \\ Gunlawadee Maneenil, M.D.
}

Division of Neonatology, Department of Pediatrics, Faculty of Medicine, Prince of Songkla University, Hat Yai, Songkhla 90110, Thailand.

Received 12 January 2021 • Revised 21 May 2021 • Accepted 27 May $2021 \bullet$ Published online 23 July 2021

\begin{abstract}
:
Objective: It remains unclear if changes in neonatal care have resulted in better outcomes for extremely preterm infants (EPTs). This study was to evaluate neonatal mortality and morbidity in EPTs.

Material and Methods: A retrospective cohort study of EPTs at a gestational age (GA) $\leq 28$ weeks, who were admitted to the neonatal intensive care unit between January 2004 and December 2018. The study was divided into 2 periods, from 2004-2010 and 2011-2018. The likelihood ratio test in Multiple Cox regression models were used to determine adjusted hazard ratios (aHR) for differences in mortality among the two periods.

Results: A total of 188 EPTs were enrolled. The overall median (interquartile range), GA and birth weight of the enrolled infants were $26(25,27)$ weeks and $780(667,875) \mathrm{g}$, respectively. The mortality rate was 66/188 $(35.1 \%)$. The mortality rate between 2004-2010 and 2011-2018 decreased from 44.6\% to 32.8\%, but was not statistically significant ( $p-v a l u e=0.170)$. Multiple Cox regression analysis of mortality rate demonstrated statistical significance with infants of 23-24 and 25-26 weeks GA VS 27-28 weeks GA [aHR 3.85, 95\% confidence interval (Cl) (1.95, 7.58), p-value<0.010] and [aHR 1.92, 95\% $\mathrm{Cl}(1.09,3.35), \mathrm{p}$-value<0.010], respectively. Pregnancy complications [aHR 2.24, 95\% Cl $(0.96,5.24), p-v a l u e=0.040)]$ and EPTs intubated VS early CPAP at birth [aHR 2.41, 95\% Cl $(1.36,4.25)$, p-value<0.010] were statistically significant. Conclusion: The mortality rate of EPTs decreased with advancing GA. Prenatal care of pregnancy complications and improving care practices might reduce the mortality rate.
\end{abstract}

Keywords: infants, morbidity, mortality, neonatal intensive care unit, prematurity

Contact: Assoc. Prof. Waricha Janjindamai, M.D.

Division of Neonatology, Department of Pediatrics, Faculty of Medicine,

Prince of Songkla University, Hat Yai, Songkhla 90110, Thailand.

E-mail: jwaricha@medicine.psu.ac.th

This is an open access article under the CC BY-NC-ND license

(http://www.jhsmr.org/index.php/jhsmr/about/editorialPolicies\#openAccessPolicy).

J Health Sci Med Res 2022;40(2):193-202 doi: 10.31584/jhsmr.2021828 www.jhsmr.org 


\section{Introduction}

Prematurity is the most important factor influencing an infant's survival and health problems. ${ }^{1}$ Advances in perinatal and neonatal care have resulted in improved survival rates of extremely preterm infants (EPTs) over the last three decades. Unfortunately, the incidence of major significant morbidity in this population is still unchanged. Although EPTs, which were defined as those with a gestational age (GA) <28 weeks, comprise of less than $1.0 \%$ of all live births, they account for approximately half of the perinatal mortality rate. ${ }^{2,3}$ Many EPTs suffer from respiratory distress syndrome (RDS), sepsis, necrotizing enterocolitis (NEC), patent ductus arteriosus (PDA), intraventricular hemorrhage (IVH), bronchopulmonary dysplasia (BPD) and retinopathy of prematurity (ROP) during their hospitalization. Advances in neonatal care such as; antenatal corticosteroids to mothers with preterm labor, administering of exogenous surfactant, modern care of the respiratory management (high frequency ventilation (HFV), use of nitric oxide, permissive hypercapnia and optimal oxygen saturation) and aggressive nutritional practice might reduce mortality and morbidities and provide better outcomes for preterm infants. ${ }^{4}$ Nonetheless, it remains unclear whether such advances have arisen in better outcomes for EPTs. Identification cause and time of death may be especially important and would guide new research and information for counseling of families. The primary objectives of the study were to evaluate and compare in-hospital neonatal mortality rate and the secondary objectives were to evaluate EPTs morbidities and associated risk factors between the two groups in a-15-year EPTs experience at Songklanagarind hospital. To compare the morbidity and mortality rates by GA, EPTs were grouped into periods, in the years 20042010 and 2011-2018. These years demarcate distinct eras in the management of the groups. The beginning period, from 2004-2010, showed the introduction of surfactant and the second period, from 2011-2018, the refinement of ventilation strategies such as use of early noninvasive ventilation, early HFV and improved nutrition policies that have significantly changed.

\section{Material and Methods}

A retrospective cohort study was conducted in a tertiary level, neonatal intensive care unit (NICU), Songklanagarind Hospital, Prince of Songkla University in Hat Yai, Songkhla, Thailand. The enrolled infants included inborn EPTs at Songklanagarind Hospital between $23^{0 / 7}$ to $28^{0 / 7}$ weeks of gestation, admitted to the NICU between January 2004 and December 2018. The exclusion criteria were the EPTs with fatal congenital anomalies and those who were moribund at the delivery room or, on admission (staff, in consultation with the parents, had made a definite decision not to contribute life support). The GA in completed weeks was based on the first day of the last menstrual period (LMP) and confirmed by a first trimester ultrasound. If an ultrasound was not available, GA estimation was conducted by the new Ballard score. ${ }^{5}$ The study was approved by the Human Research Ethics Committee of the Faculty of Medicine, Prince of Songkla University. (REC. 59-350-01-1)

Pregnancy obstetric data including, complete antenatal corticosteroid therapy was considered if at least two doses of steroids were given at least 24-hours before delivery. Pregnancy complications were defined as, clinical chorioamnionitis, antepartum hemorrhage and severe preeclampsia. The diagnosis of clinical chorioamnionitis was based on clinical criteria including, maternal fever $(\geq 38$ $\left.{ }^{\circ} \mathrm{C}\right)$ plus two other findings, including maternal leukocytosis, maternal and fetal tachycardia, uterine tenderness, and foul-smelling or purulent amniotic fluid. ${ }^{6}$ Hypothermia was defined by admission axillary temperature of less than 36.5 ${ }^{\circ} \mathrm{C}$. ${ }^{7}$ The diagnosis of RDS was based on characteristic radiographic appearance. ${ }^{8}$ Sepsis was defined by culture proven sepsis or probable sepsis. ${ }^{9}$ The diagnosis of 
hemodynamically significant PDA (hsPDA) was by left atrium: aorta ratio $>1$, ductal size $>1.5 \mathrm{~mm}$, and left-to-right shunting of blood..$^{10}$ BPD was diagnosed as supplemental oxygen for at least 28 days for an infant born before 32 weeks of gestational age, assessment was performed at 36 weeks' postmenstrual age. ${ }^{11}$ The ROP was diagnosed depending on the ophthalmologic exam and classified using the International Classification of Retinopathy of Prematurity criteria. ${ }^{12}$ Cranial ultrasonography was carried out at the first and fourth week to detect IVH, as severe intracranial hemorrhage (Grade III or IV), by a pediatric radiologist. ${ }^{13}$ NEC was diagnosed based on modified Bell's criteria, and stage $\geq$ Il was considered to be significant gastrointestinal morbidity. ${ }^{14}$ The survival rate was defined as neonates who survived to the time of discharge or back referral to the original hospital. The primary cause of death was determined specifically according to the underlying disease. For infants with autopsy findings, the cause of death depended on both autopsy and clinical findings. Immaturity was defined as the cause of death for infants born at 23 or 24 weeks $\mathrm{GA} .^{2}$

The study was divided into two periods, from, 2004 to 2010 and 2011-2018. The data and clinical parameters were demonstrated as mean (standard deviation; S.D.) or median (interquartile range, IQR). The baseline characteristics between the periods were compared using the MantelHaenszel chi-square test for categorical variables and the Kruskal-Wallis test for continuous variables. The likelihood ratio (LR) test in multiple Cox regression models were used to determine adjusted hazard ratios (aHR), and 95\% confidence intervals $(\mathrm{Cl})$ for difference in mortality between the two periods, after adjusting for potential confounding variables related to clinical therapy. Only those covariates with a p-value of $<0.020$ in bivariable analyses were included in the final regression, to achieve parsimonious models. The time to death among the periods were compared with the survival analysis using the Kaplan-Meier method. A p-value of less than 0.050 was considered as statistical significance. All statistical analyses were conducted using The R program version 3.2.2 ( $R$ foundation for statistical computing, Vienna, Austria, 2016).

\section{Results}

\section{Baseline characteristics}

During the study period, 3.7/1000 live births (194/ $52,495)$ and $3.0 \%(194 / 6,482)$ of live birth infants of NICU admissions at Songklanagarind Hospital were EPT. Five infants with lethal congenital anomaly were excluded (four with severe hydrocephalus and the other had transposition of great artery with double outlet of right ventricle) and another was moribund on admission. One hundred and eighty-eight infants were enrolled in the study. The overall median (IQR), birth weight (BW), and GA of the enrolled infants were $780(668,875) \mathrm{g}$ and $26(25,27)$ weeks, respectively. Fifty-five percent (103/188) of the infants were female, and the preponderance of the infants were born by cesarean section $(109 / 188,57.9 \%)$. The median (IQR) Apgar score at 5 minutes was $7(4,8)$ (Table 1).

There were 54 and 134 EPTs in 2004-2010 (the first period) and 2011-2018 (the second period), respectively. Seventy-eight percent (146/188) of EPTs received antenatal corticosteroid. The rate of antenatal corticosteroid use was not different between the two periods, $(p$-value=1.000). Maternal age, GA, BW, sex, Apgar score, temperature below $36.5{ }^{\circ} \mathrm{C}$ at admission and days of ventilator were similar across the periods. The cesarean section rates, surfactant administration, use of HFV, early continuous positive airway pressure (CPAP) in delivery room and inotropic drug administration were statistically higher in the second period as compared to the first period. In addition, pregnancy complications, intubation in the delivery room and use of conventional mechanical ventilator were lower among EPTs in the second period compared to the first period (Table 1). 


\section{Neonatal outcomes}

Overall, RDS was the most common principal disease in EPTs $(168 / 188,97.1 \%)$, with no significant changes over the entire study periods (Table 2). In the first period, no NEC stage $\geq 2 A$ was diagnosed, which was different from the second period, $34 / 134(25.6 \%)$ NEC stage $\geq 2 A$ infants were found ( $p$-value<0.010). Hemodynamically significant PDA rate was higher in the second period (25.0\% VS 57.6\%, p-value<0.010), this contrasted with severe BPD which was higher in the first period $(82.4 \%$ VS $42.5 \%$, p-value $=0.010$ ). Sepsis and ROP stage $\geq 2$ were not statistically different between the periods (Table 2).

Table 1 Baseline characteristics and treatment of study participants as stratified by study period

\begin{tabular}{|c|c|c|c|c|}
\hline Characteristics & $\begin{array}{l}\text { Total } \\
n=188\end{array}$ & $\begin{array}{l}2004-2010 \\
n=54\end{array}$ & $\begin{array}{l}2011-2018 \\
n=134\end{array}$ & $p$-value \\
\hline Maternal age, year & $31(25.8,37)$ & $30(24.5,37.0)$ & $32(26.0,37.0)$ & 0.170 \\
\hline Pregnancy complication, n (\%) & $157(84.4)$ & $49(94.2)$ & $108(80.6)$ & 0.040 \\
\hline First trimester ultrasound, n (\%) & $28(15.3)$ & $5(8.3)$ & $23(18.7)$ & 0.107 \\
\hline Antenatal corticosteroid, n (\%) & $146(78.1)$ & $41(77.4)$ & $105(78.4)$ & 1.000 \\
\hline Cesarean section, n (\%) & $109(58.0)$ & $22(40.7)$ & $87(64.9)$ & $<0.010$ \\
\hline Gestational age, week ${ }^{+}$ & $26(25.0,27.0)$ & $26(25.0,27.0)$ & $27(25.0,27.0)$ & 0.210 \\
\hline Birth weight, $\mathrm{g}^{+}$ & $780(668.0,875.0)$ & $810(682.5,900.0)$ & $760(650.0,860.0)$ & 0.150 \\
\hline Female, n (\%) & $103(54.8)$ & $30(55.6)$ & $73(54.5)$ & 1.000 \\
\hline Apgar score at 5 minute & $7(4.0,8.0)$ & $7(5.0,8.0)$ & $7(4.0,8.0)$ & 0.360 \\
\hline Body temperature <36.5 C, n (\%) & $148(79.1)$ & $47(87.0)$ & $101(75.9)$ & 0.140 \\
\hline ETT at birth, $\mathrm{n}(\%)$ & $110(58.5)$ & $38(70.4)$ & $72(53.7)$ & 0.050 \\
\hline Early CPAP, n (\%) & $78(41.5)$ & $16(29.6)$ & $62(46.3)$ & 0.050 \\
\hline Surfactant administration, n (\%) & $84(46.7)$ & $10(19.2)$ & $74(57.8)$ & $<0.010$ \\
\hline Days of ventilator ${ }^{+}$ & $10(3,27)$ & $10(2,29)$ & $8.5(3.0,26.5)$ & 0.730 \\
\hline Used of HFV, n (\%) & $99(56.6)$ & $10(22.2)$ & $89(68.5)$ & $<0.010$ \\
\hline Used of conventional ventilator, $\mathrm{n}(\%)$ & $76(43.4)$ & $35(77.8)$ & $41(31.5)$ & $<0.010$ \\
\hline Inotropic drug administration, n (\%) & $135(71.8)$ & $25(46.3)$ & $110(82.1)$ & $<0.010$ \\
\hline
\end{tabular}

${ }^{+}$Median (interquartile range, IQR), HFV=high frequency ventilator, ETT=endotracheal tube, CPAP=continuous positive airway pressure

Table 2 Comparing neonatal outcomes between the study periods

\begin{tabular}{|c|c|c|c|c|}
\hline Disease & $\begin{array}{l}\text { Total } \\
n=188\end{array}$ & $\begin{array}{l}2004-2010 \\
n=54\end{array}$ & $\begin{array}{l}2011-2018 \\
n=134\end{array}$ & p-value \\
\hline Respiratory distress syndrome & $168(97.1)$ & $39(95.1)$ & $129(97.7)$ & 0.340 \\
\hline Necrotizing enterocolitis stage $\geq 2 A$ & $34(19.7)$ & $0(0.0)$ & $34(25.6)$ & $<0.010$ \\
\hline Patent ductus arteriosus & $86(50.0)$ & $10(25.0)$ & $76(57.6)$ & $<0.010$ \\
\hline Intraventricular hemorrhage (grade $\geq 3$ ) & $13(16.2)$ & $3(20.0)$ & $10(15.4)$ & 0.700 \\
\hline Severe bronchopulmonary dysplasia & $48(49.5)$ & $14(82.4)$ & $34(42.5)$ & 0.010 \\
\hline Sepsis & $46(26.4)$ & $6(14.6)$ & $40(30.1)$ & 0.079 \\
\hline Retinopathy of prematurity stage $\geq 3$ & $51(29.3)$ & $11(26.8)$ & $40(30.1)$ & 0.840 \\
\hline
\end{tabular}




\section{Trends in mortality}

The overall in-hospital mortality rate in this study period was $35.1 \%(66 / 188)$. The mortality rate decreased with increasing gestational age. The mortality rate was $60.0 \%, 64.7 \%, 40.0 \%, 40.0 \%, 28.0 \%$ and $19.5 \%$ in those born at 23, 24, 25, 26, 27 and 28 weeks' gestation, respectively. There was no statistically significant difference in mortality rates by each GA between periods except EPTs at 26 weeks GA, with mortality rates higher in the first period (58.8\% VS 26.1\%, p-value=0.020) (Table 3). The mortality rates were not statistically significant between the two periods $(42.6 \%$ VS $32.1 \%$, p-value $=0.230)$ (Table 4). Death or any morbidity and infants with any morbidity were statistically significant higher in the second period (40.1\% VS $70.1 \%$, p-value $<0.010$ and $37.0 \%$ VS $68.7 \%$, $p$-value $<0.010$, respectively). Between the years 2004 and 2018, deaths were most frequently attributed to respiratory problems (39.4\%). According to postnatal age, the most common cause of deaths within 24 hours after birth was immaturity (66.0\%). For infants' death within 24 hours, there was a statistically significant higher number in the first period (39.1\% VS 9.3\%, p-value<0.010). Respiratory problems were the most common cause of death occurring
25-72 hours after birth $(59.0 \%)$. From 4 to 7,8 to 30 days and after 30 postnatal days, neonatal sepsis became the predominant cause of death. $(13.0 \%, 58.0 \%, 90.0 \%$, respectively) (Figure 1). When comparing survival analysis with Kaplan-Meier method by GA and postnatal age among the study periods, there were statistically significantly higher survival rates in EPTs at GA 25-26 weeks and GA 2728 weeks compared to 23-24 weeks ( $p-$ value $=0.020$ and $p$-value $=0.003$, respectively). The survival rate was also statistically significantly higher when compared between 27-28 weeks and 25-26 weeks GA, respectively ( $p$-value $=0.030$ ) (Figure 2).

Multiple Cox's proportional hazard model of mortality rate after adjusting for biological and perinatal variables, demonstrated the statistical significance of GA 23-24 VS 27-28 weeks [aHR 3.85, 95\% Cl (1.95, 7.58), p-value $<0.010$ ], GA 25-26 VS 27-28 weeks [aHR 1.92, 95\% Cl (1.09, 3.35), $p$-value<0.010]. Pregnancy complications [aHR 2.24, 95\% Cl $(0.96,5.24), p-v a l u e=0.010)]$ and EPTs intubated at birth VS early CPAP at birth [aHR 2.41, 95\% $\mathrm{Cl}(1.36,4.25), \mathrm{p}$-value<0.010] were statistically significant (Table 5).

Table 3 Comparing mortality rate of the extremely preterm infant according to gestational age at birth, stratified by study period

\begin{tabular}{|c|c|c|c|c|}
\hline Gestational age (week) & $\begin{array}{l}\text { Total } \\
n=66\end{array}$ & $\begin{array}{l}2004-2010 \\
n=23\end{array}$ & $\begin{array}{l}2011-2018 \\
n=43\end{array}$ & p-value \\
\hline 23 & $3 / 5(60.0)$ & $2 / 2(100.0)$ & 1/3 (33.3) & 0.280 \\
\hline 24 & $11 / 17(64.7)$ & $5 / 5(100.0)$ & $6 / 12(50)$ & 0.500 \\
\hline 25 & $14 / 35(40.0)$ & 3/9 (33.3) & $11 / 26(42.3)$ & 0.350 \\
\hline 26 & $16 / 40(40.0)$ & $10 / 17(58.8)$ & 6/23 (26.1) & 0.020 \\
\hline 27 & $14 / 50(28.0)$ & 2/13 (15.4) & 12/37 (32.4) & 0.110 \\
\hline 28 & $8 / 41$ (19.5) & $1 / 8(12.5)$ & 7/33 (21.2) & 0.240 \\
\hline
\end{tabular}


Table 4 Comparing cause of death between the study periods

\begin{tabular}{|c|c|c|c|c|}
\hline Cause of death & $\begin{array}{l}\text { Total } \\
n=188\end{array}$ & $\begin{array}{l}2004-2010 \\
n=54\end{array}$ & $\begin{array}{l}2011-2018 \\
n=134\end{array}$ & $p$-value \\
\hline Death or any morbidity, $\mathrm{n}(\%)^{+}$ & $116(61.7)$ & $22(40.7)$ & $94(70.1)$ & $<0.010$ \\
\hline Any morbidity, $\mathrm{n}(\%)^{+}$ & $112(59.6)$ & $20(37.0)$ & $92(68.7)$ & $<0.010$ \\
\hline Death, $\mathrm{n}(\%)$ & $66(35.1)$ & $23(42.6)$ & $43(32.1)$ & 0.230 \\
\hline Immaturity, n (\%) & $14(21.2)$ & $7(30.4)$ & $7(16.3)$ & 0.220 \\
\hline Respiratory disease, n (\%) & $26(39.4)$ & $10(43.5)$ & $16(37.2)$ & 0.820 \\
\hline Sepsis, n (\%) & $20(30.3)$ & $5(21.7)$ & $15(34.9)$ & 0.410 \\
\hline IVH (grade $\geq 3), \mathrm{n}(\%)$ & $6(9.1)$ & $1(4.3)$ & $5(11.6)$ & 0.660 \\
\hline
\end{tabular}

${ }^{+}$Morbidity=necrotizing enterocolitis / severe bronchopulmonary dysplasia / retinopathy of prematurity stage $\geq 3$ / sepsis / intraventricular hemorrhage grade $\geq 3$

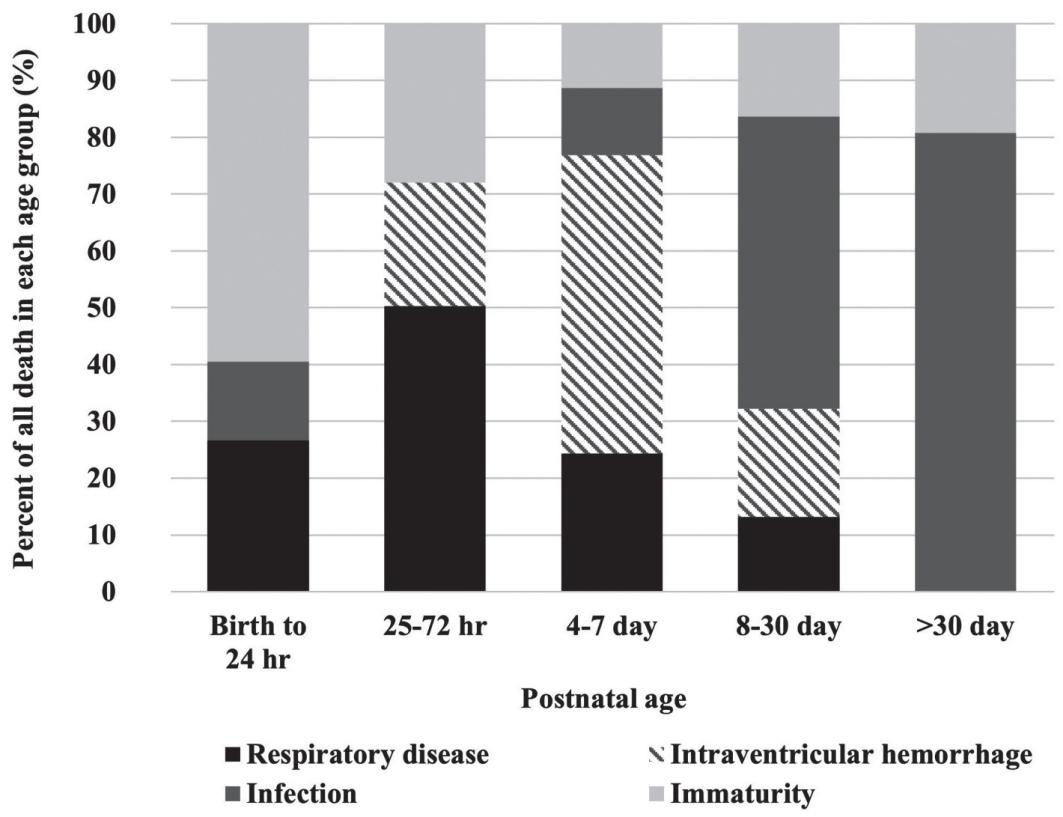

Figure 1 Proportionate mortality for major causes of death, according to postnatal age 


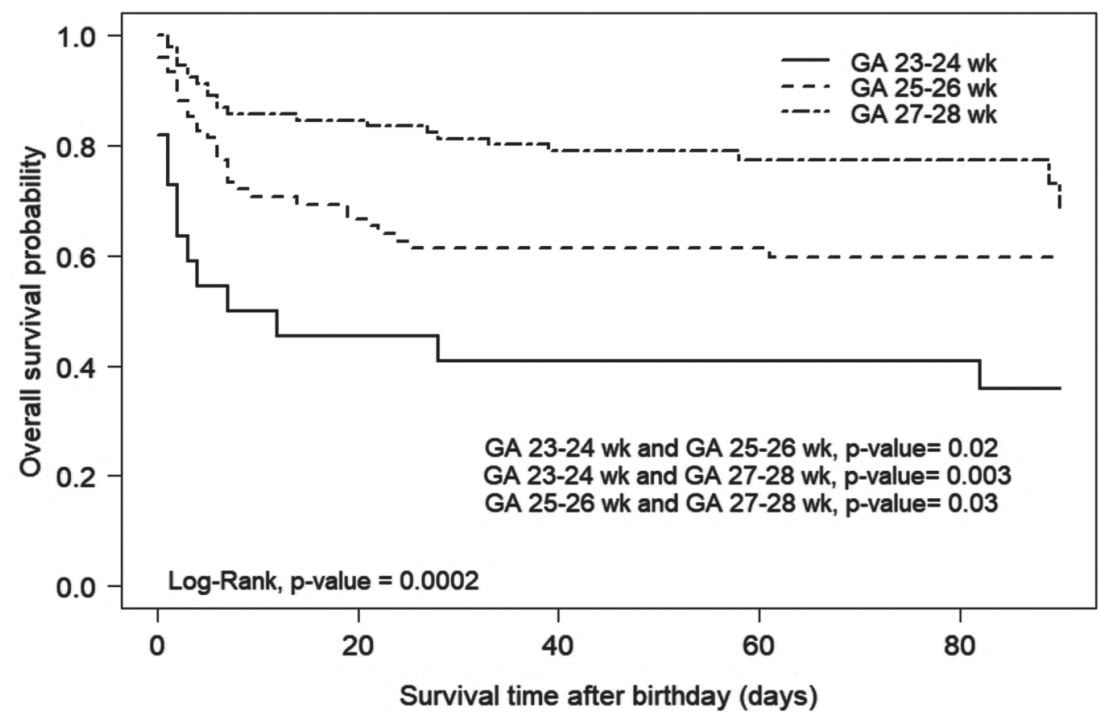

Figure 2 Comparing mortality rate of the extremely preterm infant at different gestational age at birth

Table 5 Perinatal risk factors associated with mortality by multiple Cox proportional hazard model

\begin{tabular}{lllll}
\hline Risk factors & $\boldsymbol{\beta}$ value & Wald $\boldsymbol{\chi}$ & Adjust HR (95\% Cl) & $\mathbf{p}$-value \\
\hline Gestational age (GA), week & & & & $<0.010$ \\
GA 23-24 VS GA 27-28 & 1.35 & 4.11 & $3.85(1.95,7.58)$ & \\
GA 25-26 VS GA 27-28 & 0.65 & 0.65 & $1.92(1.09,3.35)$ & \\
Pregnancy complications & 0.81 & 0.05 & $2.24(0.96,5.24)$ & 0.040 \\
ETT at birth VS early CPAP & 2.41 & 0.001 & $2.41(1.36,4.25)$ & $<0.010$ \\
\hline
\end{tabular}

$\mathrm{GA}=$ gestational age, $\mathrm{ETT}=$ endotracheal tube, $\mathrm{CPAP}=$ continuous positive airway pressure

\section{Discussion}

In this cohort study, the mortality rate and shortterm morbidities were analyzed over 15 years. After medical terminations and birth defects were excluded, the overall mortality rate of EPTs in the study period was $35.1 \%$. Even though this study could not detect a consistent direction of mortality rate between the 2 periods, it demonstrated a trend towards decreased mortality from the first period to the second period $(42.6 \%$ VS $32.1 \%, p$-value=0.230). This could be from the small population of the study. The changes in refinement of resuscitation of EPTs in the delivery room by early CPAP instead of delivery room intubation, the ventilation strategies such as use of early HFV and improved early aggressive nutrition policies, are thought to show the cumulative effects in the second period more than the first period. Overall, the mortality rate gradually decreased with advancing GA, starting at a $60.0 \%$ in infants with a GA of 23 weeks, then dropping steeply to $19.5 \%$ in infants with 28 weeks of gestation (Table 3). The mortality rate in the first period of EPTs born at 23 and 28 weeks' GA (100.0\% and 12.5\%) were higher than in the National Institute of Child Health and Human Development (NICHD) study from 1993-2012 $2^{15},(68.0 \%$ and 6.0\%). In addition, 887 EPTs were studied in Singapore, wherein 
the mortality rate between 2009 and 2012 for infants at 23 weeks GA was $81.0 \%$ and $7.0 \%$ at 28 weeks. ${ }^{16}$ The Canada Neonatal Network (CNN) demonstrated EPTs GA $<29$ weeks substantially decreased the mortality rate from $17.2 \%$ (1996-1997) to $14.7 \%$ (2006-2007). ${ }^{17}$ Moreover, this cohort was comparable to a Turkish study from 1997-2000 $(35.1 \%)^{18}$ and lower than the study from China $(63.8 \%$ in 2008 to $40.7 \%$ in 2017). ${ }^{19}$ The difference in timing of the study period, the number of study population, and practical guidelines of caring for EPTs created the different results. In this study, mortality rate at hospital discharge may be representative of our setting as a regional referral perinatal center and a tertiary university hospital in the south of Thailand. In addition, death or any morbidity as well as infants with any morbidity were statistically significantly higher in the second period $(40.1 \%$ VS $70.1 \%$, p-value< 0.010 and $37.0 \%$ VS $68.7 \%$, p-value $<0.010$, respectively). To assess the higher morbidity rate of EPTs, decreasing mortality is being replaced by increasing morbidity. ${ }^{20}$

In this study, RDS was a common cause of neonatal deaths (39.4\%), followed by neonatal sepsis (30.3\%) and then immaturity $(21.2 \%)$. This study demonstrated the most common cause of death within 24 hours after birth was immaturity $(66.0 \%)$, which concurs with the studies from the NICHD in that immaturity was the cause of death within 12 hours of life followed by RDS and BPD. ${ }^{21}$

Antenatal corticosteroid administration is one of the most effective interventions associated with higher survival and survival without major morbidities at 22 to 25 weeks' gestation. ${ }^{22}$ Among patients in this study, the rate of antenatal corticosteroid administration (78.1\%), resembled the rates reported in the $\mathrm{NICHD}^{23}$, and were not different between the study periods. This study also demonstrated a changing pattern in the significant increase of cesarean deliveries between the study periods (40.7\% VS 64.9\%) which was at a higher rate than in the EPIPAGE-2 study. ${ }^{24}$
NEC is the most serious gastrointestinal complication in EPTs with 30.0 to $40.0 \%$ of extremely low birth weight infants mortality. ${ }^{25}$ While the etiology of NEC is not fully understood, the key risk factor is postulated to prematurity. ${ }^{26}$ In the first period of this study, no NEC was reported compared to $25.6 \%$ in the second period. However, the results should be interpreted with caution, because of the small number of surviving infants born at 26 weeks GA in the first period. In addition, hsPDA were higher in the first period compared to the second period. In the second period, availability of NICU echocardiography together with well trained staff for PDA screening in high-risk infants, created an increased number of hsPDA. After adjustment for illness severity (birth weight and gestational age, use of inotropic agents and infants on endotracheal tube at birth on admission) and perinatal risks (pregnancy complications and antenatal corticosteroid used), no difference in RDS, sepsis, severe ROP and IVH grade $\geq 3$ were identified. However, severe BPD continued to be significantly higher in the first period. Difference in policies of ventilation strategies such as use of early CPAP, early HFV, improved nutrition policies and early rescue surfactant therapy decreased the incidence of BPD. ${ }^{27,28}$

This study demonstrated that EPTs who needed endotracheal intubation at birth increased risk of mortality rate when compared to early CPAP (Table 5). This concurred with the study from the SUPPORT study group. ${ }^{29}$ In addition, mortality rate decreased with increasing $G A$ similar to data from other studies. ${ }^{16,30,31}$ Unfortunately, other perinatal risk factors were not significantly associated with EPTs mortality rates such as, sex, and delivery by cesarean section that are in contrast to other studies. ${ }^{16,23}$

The strength of the study consists of a long period of data collection, a 15-year period. However, this study has some limitations. First, no long-term psychomotor developmental data were studied. However, this study 
analyzed severe short-term morbidity, which related to neurodevelopmental impairments. Second, a cohort study of infants in a single tertiary care center limits its different resources and settings. Third, this study is retrospective in nature of data for the former two time points, making statistical comparisons difficult. To improve the quality of these data, registered data could be used. Finally, the obstetrics policy might decrease the mortality rates such as in-utero referral to a perinatal center and active inhibition of labor at an extremely preterm age. These factors might interact with the active neonatal policy to improve mortality rates.

\section{Conclusions}

Mortality rate of EPTs gradually decreased with advancing GA. Prenatal care of pregnancy complications and changes in EPTs care practices might reduce the mortality rate. Understanding short-term outcomes may improve caring for EPTs and be valuable in counseling the families. Ultimately, reducing preterm birth is essential to reduce the burden of mortality and morbidity for EPTs.

\section{Acknowledgement}

The authors thank Miss Janjira Saesun (Department of Pediatrics, Faculty of Medicine, Prince of Songkla University, Thailand) for the statistical analysis, and Geoffrey Cox from the Office of International Affairs, Faculty of Medicine, Prince of Songkla University, Thailand, for editing the manuscript.

\section{Funding source}

Faculty of Medicine, Prince of Songkla University, Thailand

\section{Conflict of interest}

There are no potential conflicts of interest to declare.

\section{References}

1. Blencowe H, Cousens S, Chou D, Oestergaard M, Say L, Moller $\mathrm{AB}$, et al. Born too soon: the global epidemiology of 15 million preterm births. Reprod Health 2013;10 (Suppl 1):S2.

2. Howson CP, Kinney MV, Lawn J. Born Too Soon: the global action report on preterm birth. March of Dimes, $\mathrm{PMNCH}$, Save the Children. Geneva: WHO; 2012.

3. Martin JA, Hamilton BE, Osterman MJ. Births in the United States, 2014. NCHS Data Brief 2015;201:1-8.

4. Hack M, Fanaroff AA. Outcomes of children of extremely low birthweight and gestational age in the 1990s. Semin Neonatol 2000;5:89-106.

5. Ballard JL, Khoury JC, Wedig K, Wang L, Eilers-Walsman BL, Lipp R. New Ballard Score, expanded to include extremely premature infants. J Pediatr 1991;119:417-23.

6. Tita AT, Andrews WW. Diagnosis and management of clinical chorioamnionitis. Clin Perinatol 2010;37:339-54.

7. World Health Organization. Thermal protection of the newborn: a practical guide. Division of Reproductive Health (Technical Support), Geneva: WHO; 1997.

8. Lagoski M, Hamvas A, Wambach JA. Respiratory distress syndrome in the neonate. In: Martin RJ, Fanaroff AA, Walsh MC, editors. Fanaroff and Martin's Neonatal-Perinatal Medicine Diseases of the Fetus and Infant. $11^{\text {st }}$ ed. Philadelphia: Elsevier; 2020:p.1159-73.

9. Wynn JL, Wong HR, Shanley TP, Bizzarro MJ, Saiman L, Polin RA. Time for a neonatal-specific consensus definition for sepsis. Pediatr Crit Care Med 2014;15:523-8.

10. Evans N. Current controversies in the diagnosis and treatment of patent ductus arteriosus in preterm infants. Adv Neonatal Care 2003;3:168-77.

11. Jobe $A H$, Bancalari E. Bronchopulmonary dysplasia. Am J Respir Crit Care Med 2001;163:1723-9.

12. International Committee for the Classification of Retinopathy of $\mathrm{P}$. The International Classification of Retinopathy of Prematurity revisited. Arch Ophthalmol 2005;123:991-9.

13. Papile LA, Burstein J, Burstein R, Koffler $\mathrm{H}$. Incidence and evolution of subependymal and intraventricular hemorrhage: a study of infants with birth weights less than $1,500 \mathrm{gm}$. J Pediatr 1978;92:529-34.

14. Pumberger W, Mayr M, Kohlhauser C, Weninger M. 
Spontaneous localized intestinal perforation in very-lowbirth-weight infants: a distinct clinical entity different from necrotizing enterocolitis. J Am Coll Surg 2002;195:796-803.

15. Stoll BJ, Hansen NI, Bell EF, Walsh MC, Carlo WA, Shankaran $\mathrm{S}$, et al. Trends in Care Practices, Morbidity, and Mortality of Extremely Preterm Neonates, 1993-2012. JAMA 2015;314: 1039-51.

16. Agarwal P, Sriram B, Rajadurai VS. Neonatal outcome of extremely preterm Asian infants 28 weeks over a decade in the new millennium. J Perinatol 2015;35:297-303.

17. Shah PS, Sankaran K, Aziz K, Allen AC, Seshia M, Ohlsson A, et al. Outcomes of preterm infants $<29$ weeks gestation over 10-year period in Canada: a cause for concern? J Perinatol 2012;32:132-8.

18. Atasay B, Gunlemez A, Unal S, Arsan S. Outcomes of very low birth weight infants in a newborn tertiary center in Turkey, 1997-2000. Turk J Pediatr 2003;45:283-9.

19. Wu F, Liu G, Feng Z, Tan X, Yang C, Ye X, et al. Short-term outcomes of extremely preterm infants at discharge: a multicenter study from Guangdong province during 2008-2017. BMC Pediatrics 2019;19:405.

20. Marlow N, Bennett C, Draper ES, Hennessy EM, Morgan AS, Costeloe KL. Perinatal outcomes for extremely preterm babies in relation to place of birth in England: the EPICure 2 study. Arch Dis Child Fetal Neonatal Ed 2014;99:F181-8.

21. Patel RM, Kandefer S, Walsh MC, Bell EF, Carlo WA, Laptook $A R$, et al. Causes and timing of death in extremely premature infants from 2000 through 2011. N Engl J Med 2015;372:331-40.

22. Ehret DEY, Edwards EM, Greenberg LT, Bernstein IM, Buzas JS, Soll RF, et al. Association of Antenatal Steroid Exposure with Survival Among Infants Receiving Postnatal Life Support at 22 to 25 Weeks' Gestation. JAMA Netw Open 2018;1: e183235.
23. Stoll BJ, Hansen NI, Bell EF, Shankaran S, Laptook AR, Walsh $M C$, et al. Neonatal outcomes of extremely preterm infants from the NICHD Neonatal Research Network. Pediatrics 2010; 126:443-56.

24. Perlbarg J, Ancel PY, Khoshnood B, Durox M, Boileau P, Garel $M$, et al. Delivery room management of extremely preterm infants: the EPIPAGE-2 study. Arch Dis Child Fetal Neonatal Ed 2016;101:F384-90.

25. Fitzgibbons SC, Ching Y, Yu D, Carpenter J, Kenny M, Weldon $C$, et al. Mortality of necrotizing enterocolitis expressed by birth weight categories. J Pediatr Surg 2009;44:1072-5.

26. Cristofalo EA, Schanler RJ, Blanco CL, Sullivan S, Trawoeger $\mathrm{R}$, Kiechl-Kohlendorfer $\mathrm{U}$, et al. Randomized trial of exclusive human milk versus preterm formula diets in extremely premature infants. J Pediatr 2013;163:1592-5.e1.

27. Nelin LD, Bhandari V. How to decrease bronchopulmonary dysplasia in your neonatal intensive care unit today and “tomorrow”. F1000 Res 2017;6:539.

28. Isayama T. The clinical management and outcomes of extremely preterm infants in Japan: past, present, and future. Transl Pediatr 2019;8:199-211.

29. Network SSGotEKSNNR, Finer NN, Carlo WA, Walsh MC, Rich W, Gantz MG, et al. Early CPAP versus surfactant in extremely preterm infants. N Engl J Med 2010;362:1970-9.

30. Kugelman A, Bader D, Lerner-Geva L, Boyko V, Levitzki O, Riskin $\mathrm{A}$, et al. Poor outcomes at discharge among extremely premature infants: a national population-based study. Arch Pediatr Adolesc Med 2012;166:543-50.

31. Patel RM. Short- and Long-Term Outcomes for Extremely Preterm Infants. Am J Perinatol 2016;33:318-28. 